\title{
Fluid Shear Stress Inhibits Differentiation of Growth Plate Chondrocytes, Partially Via Integrin Beta 1
}

\author{
Tracy A Denison ${ }^{1}$, Maryam Doroudi ${ }^{2}$, Zvi Schwartz ${ }^{3,4}$ and Barbara D Boyan ${ }^{1,2,3 *}$ \\ ${ }^{1}$ Department of Biomedical Engineering, Georgia Institute of Technology and Emory University, USA \\ ${ }^{2}$ School of Biology, Georgia Institute of Technology, USA \\ ${ }^{3}$ School of Engineering, Virginia Commonwealth University, USA \\ ${ }^{4}$ Department of Periodontics, University of Texas Health Science Center at San Antonio, USA
}

Submission: March 28, 2017; Published: April 06, 2017

"Corresponding author: Barbara D Boyan, School of Engineering Virginia Commonwealth University, 601 West Main Street, Richmond, VA 23284-3068, USA, Tel: 804-828-0190; Fax: 804-828-9866; Email: bdboyan@vcu.edu

\begin{abstract}
Mechanical stimuli such as fluid shear stress contribute to cartilage homeostasis and serve as important parameters for tissue engineering bioreactors. While mechanical forces on articular chondrocytes are widely investigated, the objective of this study was to determine the effects of fluid shear stress on growth plate cartilage cells. Rat costochondral resting zone chondrocytes (RC) and chondrogenic ATDC5 cells were subjected to $0,2,3.5,5$, or 6.5 dynes/cm2 fluid shear stress in a cone-plate viscometer device for 24 hours, and thenwereharvested immediately or after an additional static culture period. Shear stress exposure decreased [35S]-sulfate and [3H]-thymidine incorporation, but these were partially or fully recovered to control levels following a 24-hour, post-shear static culture across shear treatments. Alkaline phosphatase activity was also dose-dependently lowered by shear at this interval. Shear stress significantly increased mRNAs for integrins beta 1(Itgb1), alpha 2 (Itga2), and alpha 5 (Itga5) and decreased aggrecan (Acan) expression at the end of shear exposure, but mRNAs for integrin beta 3 (Itgb3), collagen type II, alpha 1 (Col2a1) and cartilage oligomeric matrix protein (Comp) did not change. At 12 hours post shear exposure, the expression levels of Itgb1, Itga2, and Itga5 returned to the control levels, whereas the expression of chondrogenic markers was decreased significantly. Silencing Itgb1 in ATDC5 cells did not alter shear-mediated effects on cell number, alkaline phosphatase, or [35S]-sulfate incorporation, but it did prevent reduction of Col2 and Comp mRNA expression in response to shear.
\end{abstract}

Keywords: Fluid shear stress; Growth plate; ATDC5 cells; Mechano transduction, Integrin

\section{Introduction}

The mechanical environment is an important parameter for the homeostatic function of chondrocytes [1]. Numerous studies have considered the effect of shear stress on mature normal [2] or arthritic [3] chondrocytes in vitro and in the joint tissues, like articular cartilage [4,5] or meniscal fibro-cartilage [6,7]. Cartilage is a highly hydrated tissue that experiences movement of fluid when compression is applied, resulting in potential fluid shear stress along the cellular membrane [8]. Studies of tissue engineered cartilage show that changes in fluid shear stress in a bioreactor can modulate growth and differentiation of the cells and that effects change as the cells produce extracellular matrix (ECM) $[9,10]$.

How fluid shear affects chondrocytes may involve many mechanisms including changes in membrane potential, solute transport, or cellular deformation [11]. Integrin related stretch ion channels may also be involved [8], and integrins have been shown to potentially mediate many effects of mechanotransduction [12,13]. Integrin beta 1 (ITGB1) subunit blocking with antibodies or RGD peptides has been shown to prevent both mechanically stimulated increases $[13,14]$ and decreases [15] in cartilage matrix markers.

Mechanical loading may play a role in joint formation as early as fetal development, such as in the temporal-mandibular joint [16] and hip [17], but very little is known about effects of fluid shear on chondrocytes in the developing growth plate. The mammalian growth plate is a remaining center of endochondral ossification that persists after embryonic development of long bones. How growth plate chondrocytes respond to shear throughout endochondral bone formationis not well understood. It may change markedly with the state of chondrocyte maturation within the growth plate. Moreover, any role of integrins in responding to mechanical stresses for growth 
plate cells is not well studied. However, conditional knock-out studies have shown that the absence of the ITGB1 subunit in vivo results in disorganized growth plate development in mouse embryos [18]. This suggests a vital role of this subunit in growth plate orientation and differentiation, which in turn supports the hypothesis that integrins in the growth platemay exhibit mechano-responsive roles similar to those observed in articular chondrocytes.

The present study determined how changes in fluid shear force modulate the behavior of chondrocytes from the growth plate, and how ITGB1 mediates that response. The chondrocyte phenotype varies both temporally and spatially during endochondral ossification. Not only do the cells show changes in shape and size, but they also vary in their extracellular matrix (ECM) composition and in their responses to local and systemic factors [19]. To limit potential variables in the present study, we focused on chondrocytes in the resting zone (RC) of the growth plate, which are characterized by sulfated proteoglycanrich, type II collagen ECM. We used two models: primary rat costochondral cartilage RC chondrocytes and the chondrogenic embryonic murine ATDC5 cell line. Rat RC cells retain phenotypic properties of resting zone cells in vivo, including synthesis of type II collagen but not type $\mathrm{X}$ collagen, zone specific responses to vitamin D metabolites $1 \alpha, 25(\mathrm{OH}) 2 \mathrm{D} 3$ and $24 \mathrm{R}, 25(\mathrm{OH}) 2 \mathrm{D} 3$, and low matrix metalloproteinase activity [20].

\section{Methods and Materials}

\section{Cell culture}

Primary RC chondrocytes were obtained from costochondral junctions of 125-gram male Sprague Dawley rats and cultured to fourth passage as described previously [21], whereupon they were exposed to shear as described below. ATDC5 cells were cultured with a method previously shown to induce an RC-like phenotype based on chondrocytic differentiation and sensitivity to 24R, 25(OH)2D3 [22]. Briefly, ATDC5 cells were cultured in maintenance medium (MM) consisting of a 1:1 ratio of DMEM/ F12 media (Cellgro ${ }^{\circledR}$, Manassas, VA) containing 5\% FBS, and $10 \mu \mathrm{g} / \mathrm{ml}$ human transferrin (Sigma Chemical Company, St. Louis, MO), 1\% penicillin-streptomycin (Invitrogen, Carlsbad, $\mathrm{CA}$ ), and $3 \times 10^{-8} \mathrm{M}$ sodium selenite (Sigma). After reaching confluence, cells were cultured with differentiation medium (DM), which is identical to MM with the addition of $10 \mu \mathrm{g} /$ $\mathrm{ml}$ bovine insulin (Sigma) and $50 \mu \mathrm{g} / \mathrm{ml}$ ascorbic acid [23]. At 10 days post-confluence, cells were cultured for 24 hours in DM supplemented with $20 \mathrm{mM}$ phosphate (Pi) beyond medium basal level and 10\% FBS. ATDC5 cells were returned to DM and were subjected to shear stress on day 11.

\section{Application of shear stress}

Shear stress was applied to cells via a unidirectional coneplate viscometer device modeled after the design used by Dr. Hanjoong Jo (Emory University, Atlanta, GA) [24,25], which was adapted from other reported designs $[26,27]$. The device was operated at a low Reynolds number $(\operatorname{Re}<1)$, allowing shear stress $\tau$ to be estimated by the equation $\tau=\mu \omega / \alpha$, where $\mu$ is viscosity of the media, $\omega$ is angular velocity of the cone, and $\alpha$ is angle of the cone to the culture surface. Cultures were exposed to estimated shear forces ranging from 2-6.5 dynes/cm2. A static control set of cultures was included in each experiment. All cells were cultured in monolayers in $10 \mathrm{ml}$ of medium in $100 \mathrm{mmx} 20 \mathrm{~mm}$ Petri dishes (BD Falcon, Franklin Lakes, NJ). Shear exposure was for $24 \mathrm{~h}$, after which cells were either harvested for assay immediately or were given fresh media and allowed up to 24 hours of static conditions before harvesting.

\section{Cell number and viability}

At harvest, cells were washed twice with DMEM and trypsinized (Invitrogen) for 10 minutes. Cells were resuspended in saline and were counted (Beckman Coulter Z1 Particle Counter, Fullerton, CA). To determine if a decrease in cell number was due to cell detachment caused by shear, cell number was also measured immediately following shear. In this case, both the adherent cell monolayer and cells suspended in the mediumwere collected and analyzed separately. To determine if shearing had caused cell death of RC cells a two-color fluorescent stain was performed using the Molecular Probes LIVE/DEAD Viability/ Cytotoxicity Assay Kit (Invitrogen). The post-confluent ATDC5 cultures were too dense to test appropriately with this kit.

\section{Alkaline Phosphatase Activity}

Alkaline phosphatase (orthophosphoric monoester phosphohydrolase, alkaline)-specific activity was used as an indication of chondrocyte differentiation. Cells were harvested at 24 hours after shear and suspended in $0.05 \%$ Triton X-100. After three rapid freeze-thaw cycles to lyse the cells, enzyme activity was measured in cell lysates and normalized by protein content determined by using the Macro BCA Protein Assay Kit (Pierce, Rockford, IL).

\section{DNA synthesis}

DNA synthesis in RC cells was determined by measuring [3H]-thymidine (Perkin Elmer, Waltham, MA) incorporation as previously described [28]. When RC cells were $\sim 70 \%$ confluent, they were synchronized in starvation medium (1\% FBS) for 48 hours, after which they were returned to medium containing $10 \%$ FBS and received 24 hours of shear stress. Samples were assayed for [3H]-thymidine incorporation either following shear or at 24 hours later. The cultures received a 2-hour pulse of $[3 \mathrm{H}]$-thymidine either immediately after shear or at 22 hours after shear. Radioactivity in trichloroacetic acidprecipitated material was measured by liquid scintillation spectroscopy. $[3 \mathrm{H}]$-Thymidine incorporation was not measured in ATDC5 cells because their culture method is not compatible with preconfluent starvation.

\section{[35S]-Sulfate incorporation}

To determine the role of shear stress in modulating ECM composition, [35S]-sulfate incorporation was measured as an 
indicator of sulfated glycosaminoglycan production as described previously [29]. [35S]-sulfate (Perkin Elmer) was added to the cultures 4 hours prior to harvest. For samples returning to static culture after shear, [35S]-sulfate was pulsed into the medium at 20 hours after shear. To determine [35S]-sulfate incorporation directly following shear, the [35S]-sulfate pulse was applied to the cells immediately following the end of shear for 4 hours. Cell layers were collected and dialyzed to remove any unbound [35S]-sulfate. [35S] -sulfate incorporated into the cell layer was expressed as disintegrations per minute normalized to protein level.

\section{mRNA analysis with quantitative real-time PCR}

RNA was extracted using the TRIzol reagent kit (Invitrogen) and was quantified using the Nanodrop-1000 Spectrophotometer (Thermo Scientific, Waltham, MA). Reverse transcriptase was performed using the RT Omniscript Kit (Qiagen, Valencia, CA) and random primers (Promega, Madison, WI) to generate a cDNA library of each sample. Real-time PCR was performed to quantify the effects of shear on mRNA expression forchondrocytic markers aggrecan (Acan), collagen type II, alpha 1 (Col2a1), and cartilage oligomeric matrix protein (Comp), as well as multiple integrin subunits. RNA was isolated from RC and ATDC5 cells at the end of 24 hours of shear $\left(6.5\right.$ dynes $\left./ \mathrm{cm}^{2}\right)$ and 12 hours following the end of shear after returning to static culture. The primer sequences used can be found in the Online Resource Tables S1-S3.

Table S1: Primers for ATDC5 Cells.

\begin{tabular}{|c|c|c|}
\hline Protein & Sense Primer & Anti-sense Primer \\
\hline Aggrecan & $\begin{array}{c}\text { 5'-GGT CTG TGC CAT } \\
\text { CTG } \\
\text { TGA GG-3' }\end{array}$ & $\begin{array}{c}\text { 5'-CCC AGT CCA GCC } \\
\text { GAG AAA TG-3' }\end{array}$ \\
\hline $\begin{array}{l}\text { Collagen } \\
\text { type II }\end{array}$ & $\begin{array}{c}\text { 5'-TGG AGC AGC AAG } \\
\text { AGC } \\
\text { AAG G-3' }\end{array}$ & $\begin{array}{l}\text { 5'-GTG GAC AGT AGA } \\
\text { CGG AGG AAA G-3' }\end{array}$ \\
\hline COMP & $\begin{array}{l}\text { 5'-AAT ACG GTC ATG } \\
\text { GAA TGT GAT G-3' }\end{array}$ & $\begin{array}{c}\text { 5'-TCT CGG AGC AGA } \\
\text { CTA CGC-3' }\end{array}$ \\
\hline GAPDH & $\begin{array}{c}\text { 5'-TTC AAC GGC ACA } \\
\text { GTC } \\
\text { AAG G-3' }\end{array}$ & $\begin{array}{c}\text { 5'-TCT CGC TCC TGG } \\
\text { AAG ATG G-3' }\end{array}$ \\
\hline
\end{tabular}

Table S2: Primers for Resting Zone Chondrocytes*.

\begin{tabular}{|c|c|c|}
\hline \multirow{2}{*}{ Protein } & Sense Primer & Anti-sense Primer \\
\hline \multirow{3}{*}{ Aggrecan } & $\begin{array}{c}\text { 5'-AGG TGT CAC TTC } \\
\text { CCA } \\
\text { ACT ATC C-3' }\end{array}$ & $\begin{array}{c}\text { 5'-GCT TCG CTG TCC } \\
\text { TCA ATG C-3' }\end{array}$ \\
\hline GAPDH & $\begin{array}{c}\text { 5'-AAG TTC AAC GGC } \\
\text { ACA }\end{array}$ & $\begin{array}{c}\text { 5'-CAT ACT CAG CAC } \\
\text { CAG }\end{array}$ \\
& GTC AAG G-3' & CAT CAC C-3' \\
\hline
\end{tabular}

Table S3: Primers for Integrins for Both ATDC5 and RC Cells.

\begin{tabular}{|c|c|c|}
\hline Protein & Sense Primer & Anti-Sense Primer \\
\hline Beta1 & $\begin{array}{c}\text { 5'-ATT ACT CAG ATC } \\
\text { CAA CCA C-3' }\end{array}$ & $\begin{array}{c}\text { 5'-TCC TCC TCA TTT } \\
\text { CAT TCA TC-3' }\end{array}$ \\
\hline Beta3 & $\begin{array}{c}\text { 5'-ATA TGC CAC CTG } \\
\text { CCT CAA C-3' }\end{array}$ & $\begin{array}{c}5^{\prime} \text {-GCT CAC CGT GTC } \\
\text { TCC AAT C-3' }\end{array}$ \\
\hline Alpha2 & $\begin{array}{c}\text { 5'-ACT GTT CAA GGA } \\
\text { GGA GAC-3' }\end{array}$ & $\begin{array}{c}\text { 5'-GGT CAA AGG CTT } \\
\text { GTT TAG G-3' }\end{array}$ \\
\hline Alpha5 & $\begin{array}{c}\text { 5'-ATC TGT CTG CCT } \\
\text { GAC CTG-3' }\end{array}$ & $\begin{array}{c}\text { 5'-AAG TTC CCT GGG } \\
\text { TGT CTG-3' }\end{array}$ \\
\hline
\end{tabular}

\section{Silencing ATDC5 Itgb1 mRNA}

To silence integrin beta 1 (Itgb1) mRNA, ATDC5 cells were plated at 30,000 cells $/ \mathrm{cm} 2$ to achieve 70 percent confluence at 24 hours. The cells were then incubated using Mission $\AA$ lentiviral particles (Sigma) at a multiplicity of infection (MOI) of 7.5. After 18 hours, the medium was changed to regular maintenance medium for ATDC5 cells for 24 hours. Thereafter cells were cultured in maintenance medium with $2.25 \mu \mathrm{g} /$ $\mathrm{mL}$ puromycin (Sigma Aldrich) to select for only those cells successfully incorporating the new plasmid, which was also designed to induce puromycin resistance. Silencing was verified using real-time PCR and Western blot.

\section{Western blot}

Whole-cell lysates were isolated by using radioimmuno precipitation (RIPA) lysis buffer (20mM Tris-HCL, $150 \mathrm{mM} \mathrm{NaCl}$, $5 \mathrm{mM}$ disodium EDTA, ddH20, Nonidet P-40) with homogenization in Wheaton glass tissue homogenizers and sonication, followed by the addition of Laemmli sample buffer containing $0.5 \%$ 2-mercaptoethanol and boiling for 5 minutes. Samples were separated by gel electrophoresis on 4-20\% Long Life Mini Gels (NuSep, Lawrenceville, GA) and transferred to a nitrocellulose membrane using the iBlot $^{\mathrm{TM}}$ Gel Transfer Device (Invitrogen). The membranes were blocked with $2 \%$ bovine serum albumin for one hour at room temperature. After removing the blocking solution, the membrane was rocked at $4^{\circ} \mathrm{C}$ in primary antibody overnight for ITGB1 (Santa Cruz, Santa Cruz, CA) or GAPDH, (Millipore, Billerica, MA). The primary antibody was discarded, and the membrane was washed in buffer three times for a total of 30 minutes. Then the correct HRP-conjugated secondary antibody (Jackson Immuno Research, West Grove, PA, or BioRad) was added to the membrane, which rocked for one hour at room temperature, then washed again in buffer as before. Chemiluminescent bands were visualized on Versa Doc (BioRad) using the Quantity One software (Bio-Rad) for Windows.

\section{Statistical analysis}

The shearing apparatus accommodates eight simultaneously operating cone-plate devices, and each independent experiment generally had a shear treated group $(n=8)$ and a static control group $(n=8)$. Single independent experiments were analyzed with Student's t-test between the means of the static control 
and the sheared groups. In addition, a treatment-to-control ratio (fold change) was calculated for each individual experiment using those means, and multiple fold changes from replicate experiments using equivalent shear stress levels were tested with a one sample t-test to compare to a hypothetical mean of 1. All comparisons of fold change across multiple experiments at different shear levels were analyzed by ANOVA followed by Bonferroni's modification of Student's t-test. Differences were considered statistically significant at $\mathrm{P}<0.05$. Data displayed from single experiments is representative generally of multiple repeated experiments.

\section{Results}

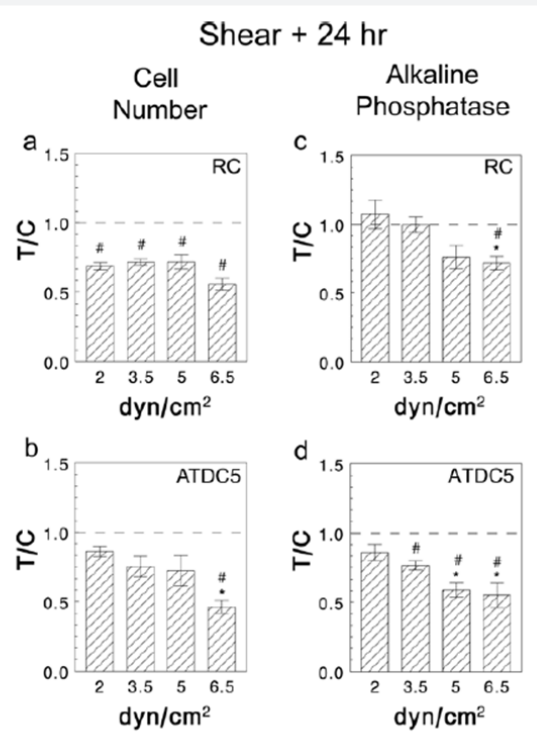

Figure 1: Shear stress reduces cell number and alkaline phosphatase activity in resting zone chondrocytes and ATDC5 cells. All bar graphs represent average treatment/control (T/C) ratios of three independent experiments of cells receiving shear stress treatment (2-6.5 dynes/cm2) for 24 hours followed by another 24 hours of static culture before harvest.

(a) Resting zone chondrocyte (RC) cell number.

(b) ATDC5 cell number.

(c) RC alkaline phosphatase specific activity.

(d) ATDC5 alkaline phosphatase specific activity \# $\mathrm{P}<0.05$ vs. hypothetical mean of 1 (or no change from static control within each level of shear treatment), ${ }^{*} \mathrm{P}<0.05$ vs. 2 dynes $/ \mathrm{cm}^{2}$.

Resting zone cells exhibited decreased cell numbers 24 hours following the termination of shear compared to cells cultured under constant static conditions; this reduction was comparable at all levels of shear stress tested (Figure 1a). ATDC5 cell number was also reduced in cultures exposed to shear stress, but this was significant only in cultures exposed to 6.5 dynes $/ \mathrm{cm}^{2}$ (Figure 1b).

At 24 hours after the end of shear, alkaline phosphatase specific activity in cell lysates was decreased in response to increasing shear treatment. Decreases were observed in RC cells at 6.5 dynes $/ \mathrm{cm}^{2}$ compared to static control cultures as well as to cultures only receiving 2 dynes $/ \mathrm{cm}^{2}$ (Figure $1 \mathrm{c}$ ). Effects of shear on alkaline phosphatase in ATDC5 cells were dosedependent, with decreased activity in cultures exposed to shear stress greater than 3.5 dynes $/ \mathrm{cm}^{2}$ compared to static control cultures and activity in cultures treated with 5 or more dynes/ $\mathrm{cm} 2$ compared to cultures exposed to 2 dynes $/ \mathrm{cm}^{2}$ (Figure $1 \mathrm{~d}$ ).

Table S4: Cells remain adherent during highest shear treatment. RC and ATDC 5 cells were sheared for 24 hours at 6.5 dynes $/ \mathrm{cm}^{2}$ and then harvested immediately for cell number, with results shown in table. Adherent cells (monolayer) were measured separately from detached cells (media) suspended in the culture media for both sheared samples and static controls. Mean (AVG) and standard error (SE) are shown. No statistically significant differences were observed between groups, and number of cells detached in media was negligible compared to adherent cells.

\begin{tabular}{|c|c|c|c|}
\hline \multirow{2}{*}{ Cell Type } & \multirow{2}{*}{ Treatment } & \multicolumn{2}{|c|}{ Cell Number $\left(10^{6}\right)$} \\
\hline & & AVG & SE \\
\hline $\mathrm{RC}$ & $\begin{array}{c}\text { Static } \\
\text { Monolayer }\end{array}$ & 2.48 & 0.12 \\
\hline $\mathrm{RC}$ & Static Media & 0.04 & 0.01 \\
\hline $\mathrm{RC}$ & $\begin{array}{c}\text { Sheared } \\
\text { Monolayer }\end{array}$ & 2.38 & 0.20 \\
\hline $\mathrm{RC}$ & Sheared Media & 0.02 & 0.01 \\
\hline ATDC5 & $\begin{array}{c}\text { Static } \\
\text { Monolayer }\end{array}$ & 22.32 & 0.58 \\
\hline ATDC5 & Static Media & 0.08 & 0.01 \\
\hline ATDC5 & $\begin{array}{c}\text { Sheared } \\
\text { Monolayer }\end{array}$ & 21.75 & 1.46 \\
\hline ATCD5 & Sheared Media & 0.18 & 0.04 \\
\hline
\end{tabular}

Reductions in cell number in shear-treated cultures were not due to cell detachment during shear. There were no differences in the number of cells in the sheared monolayer compared to the static monolayer for either cell type immediately following shear (Table S4). Furthermore, the number of cells suspended in the medium was less than $1 \%$ of the number of cells in the monolayer for both cell types. Primary RC cells exposed to 24 hours of shear stress were also stained for a live/dead assessment at the very end of shear treatment and showed overwhelming positive staining as viable (Figure S1).

Reduction in cell number was due in part to reduced DNA synthesis. At thecessation of shear stress, there was a significant reduction in [3H]-thymidine incorporation in all RC cell cultures exposed to shear (Figure 2a). However, DNA synthesis was restored to control levels in nearly all shear-treated groups, except for 3.5 dynes $/ \mathrm{cm}^{2}$, following the 24 hour recovery period. 


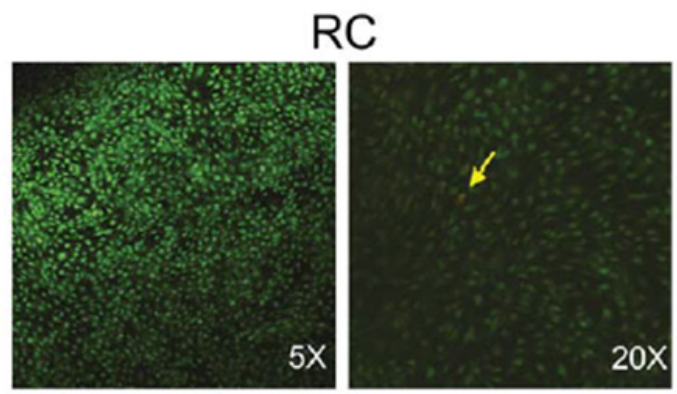

Supplemental Figure1: Cells remain viable during highest shear treatment. Primary RC cells were sheared for 24 hours at 6.5 dynes/cm2 and then harvested immediately for live (green) or dead (red) staining. The adherent cells were viable with very few dead cells observed (example of dead cell shown with arrow at higher magnification).

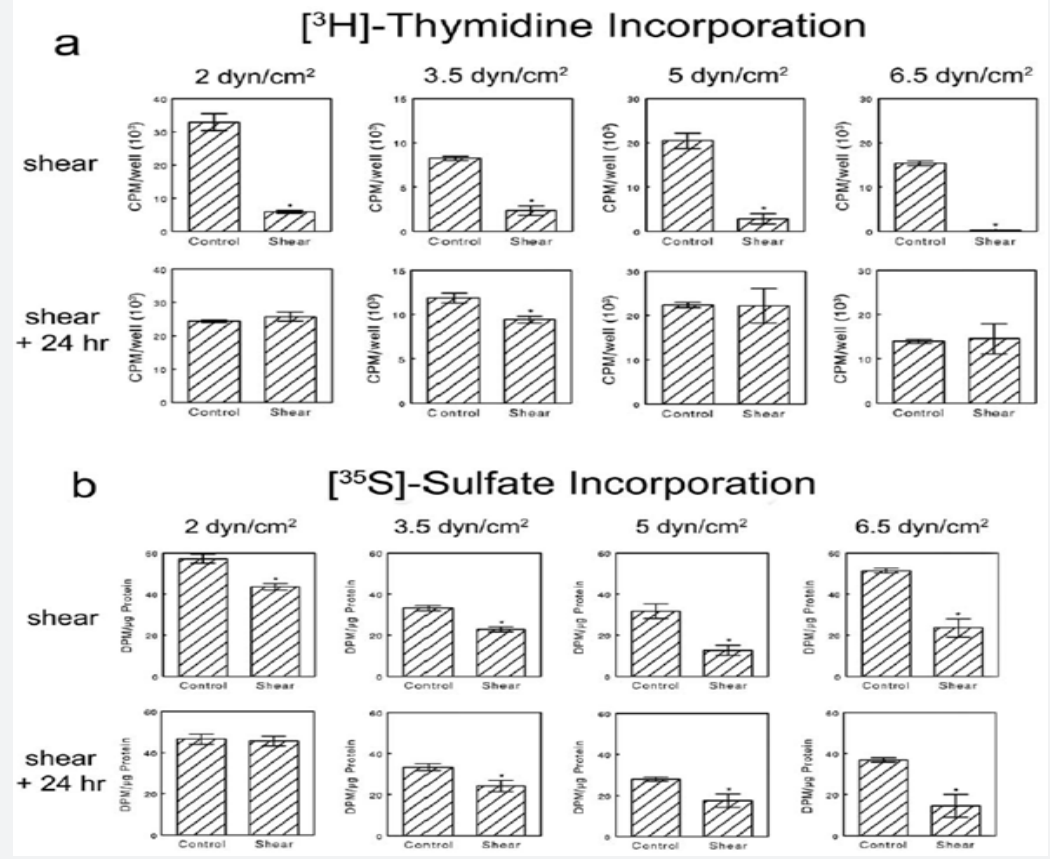

Figure 2: $[3 \mathrm{H}]-$ Thymidine and [35S]-sulfate incorporation of resting zone chondrocytes are inhibited during fluid shear stress and recover after shear.

a) $[3 \mathrm{H}]$-Thymidine incorporation by RC chondrocyte cell layers treated for 24 hours with 2 to 6.5 dynes/cm2 shear stress or under static control conditions. Incorporated label was measured promptly following the 24-hour shear stress treatment (top row) or after an additional 24 hours of post-shear, static conditions (bottom row).

b) [35S]-Sulfate incorporation into RC cell layers treated for 24 hours with $2-6.5$ dynes/cm2 shear stress (shear level organized across columns) or under static control conditions. Incorporated label was measured promptly following shear stress (top row of each panel) or 24 hours after termination of shear stress treatment (bottom row of each panel). Data presented are from a single representative experiment, all with comparable results. Values shown are means + SEM for $n=8$ static cultures and $n=8$ treated cultures for each shear condition. * $\mathrm{P}<0.05$ vs. Static Control.

Exposure to shear stress at all levels tested caused a significant decrease in [35S]-sulfate incorporation in RC cell cultures (Figure 2b), with an approximate $50 \%$ decreasein cultures exposed to the stronger 5 and 6.5 dynes $/ \mathrm{cm}^{2}$ shear. By 24 hours after shear stress, [35S]-sulfate incorporation returned to static control levels in cultures exposed to 2 dynes $/ \mathrm{cm}^{2}$ but was still lower in cultures exposed to $3.5,5$, or 6.5 dynes $/ \mathrm{cm}^{2}$. ATDC5 cells were affected in a similar manner (Figure S2).
The cells generally exhibited the most dramatic response to the highest level of shear stress applied ( 6.5 dynes $\left./ \mathrm{cm}^{2}\right)$, so this level of shear was used to observe how shear stress affected mRNA expression. Shear stress differentially altered mRNA levels for cartilage ECM proteins (Figure 3). Acan mRNA was reducedduring shear in both RC and ATDC5 cells and remained low at 12 hours post-shear. In contrast, Col2a1 mRNA and Comp mRNA were not altered during shear in either cell type. However, Col2a1 mRNA was reduced after a 12-hour post-shear period in 
both RC and ATDC5 cells whereas only ATDC5 cells exhibited a decrease in Comp mRNA levels at that time.

Supplemental Figure2: Fluid shear stress reduces [35S]-sulfate incorporation of ATDC5 cells and dose-dependently affects post-shear recovery rate. [35S] -Sulfate incorporation into cell layers treated for 24 hours with $2-6.5$ dynes $/ \mathrm{cm}^{2}$ shear stress (shear level organized across columns) or under static control conditions. Incorporated label was measured immediately following shear stress (top row of each panel) or 24 hours after shear stress (bottom row of each panel). Data presented are from a single representative experiment, all with comparable results. Values shown are means + SEM for $n=8$ static cultures and $n=8$ treated cultures for each shear condition. ${ }^{*} P<0.05$ vs. Static Control.
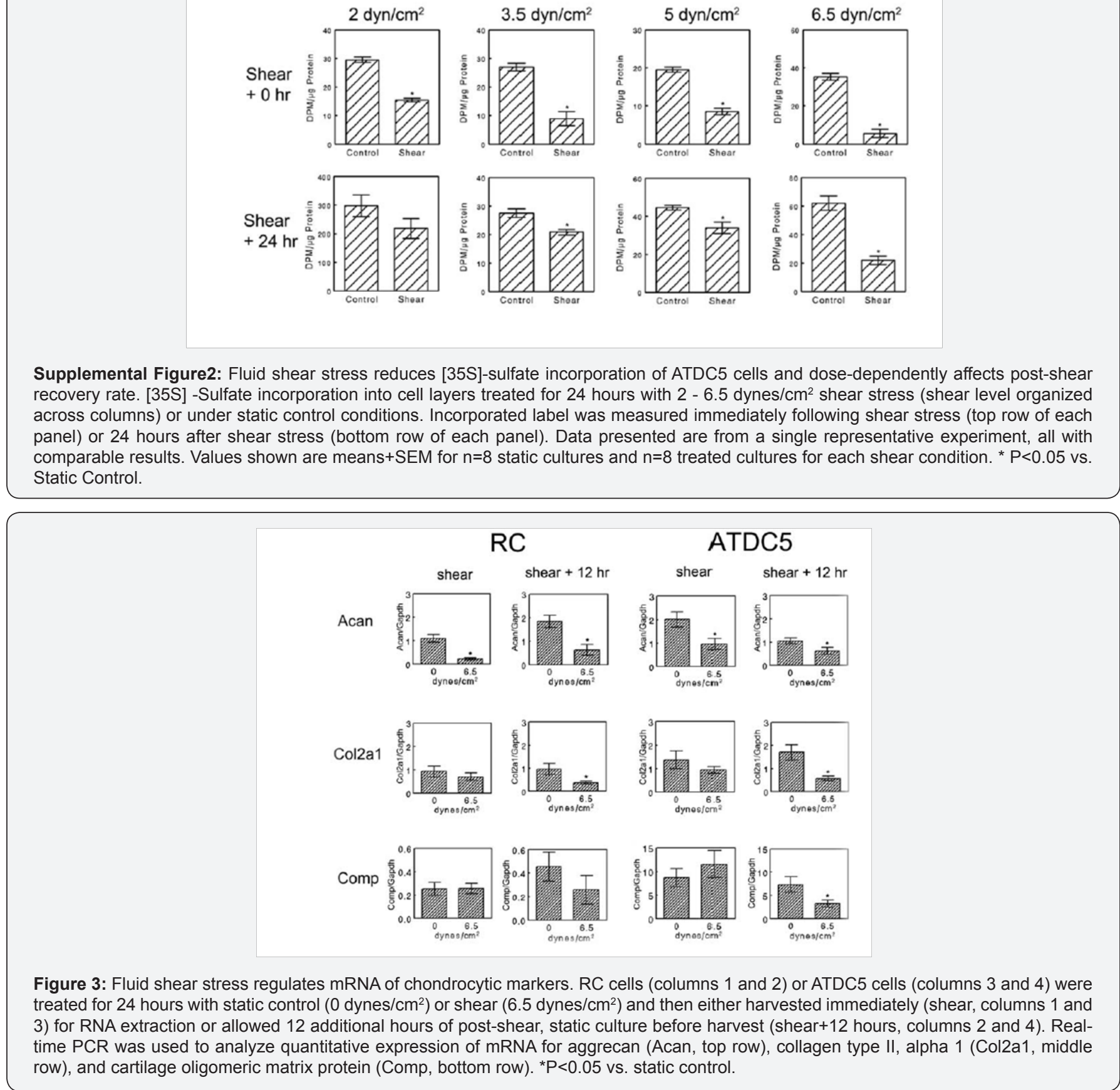

Many integrin subunit mRNA levels were significantly upregulated during shear stress in ATDC5 cells (Figure 4). mRNA for integrin alpha 2 (Itga2) and integrin alpha 5 (Itga5) were significantly higher in ATDC5 cells at the end of shear but became comparable to control levels by 12 static hours following the end of shear. Resting zone chondrocytes exhibited a similar trend although not statistically significant. Expression of Itgb1 mRNA was upregulated by shear stress consistently in both cell types. Levels were significantly higher in both ATDC5 cells and resting zone chondrocytes at the end of shear exposure.In both cell types, however, Itgb1 mRNA levels were comparable to control by 12 hours following the end of shear stress. Integrin beta 3 (Itgb3) showed a similar trend upwards at the end of shear, although not significantly different at that time or by 12 hours later. 


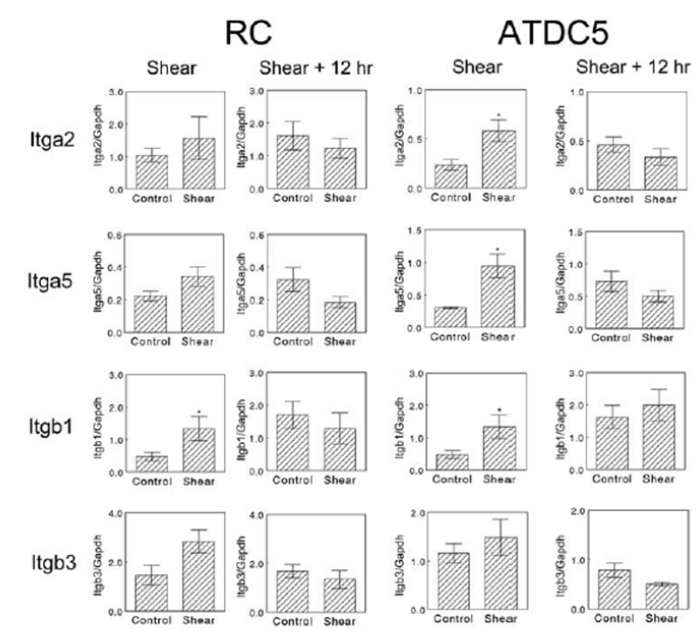

Figure 4: Shear stress increases mRNA of some integrin subunits during shear. RC cells (columns 1 and 2 ) or ATDC5 cells (columns 3 and 4$)$ were treated for 24 hours with static control $\left(0\right.$ dynes $\left./ \mathrm{cm}^{2}\right)$ or shear $\left(6.5\right.$ dynes $\left./ \mathrm{cm}^{2}\right)$ and then either harvested immediately $($ shear, columns 1 and 3 ) for RNA extraction or allowed 12 additional hours of static culture before harvest (shear +12 hours, columns 2 and 4 ). Real-time PCR was used to assess changes in mRNA levels of integrins alpha 2(Itga2) (first row), alpha 5 (Itga5) (second row), beta 1 (Itgb1) (third row), and beta 3 (Itgb3) (fourth row) at these time points. ${ }^{*} \mathrm{P}<0.05$ vs. static control.

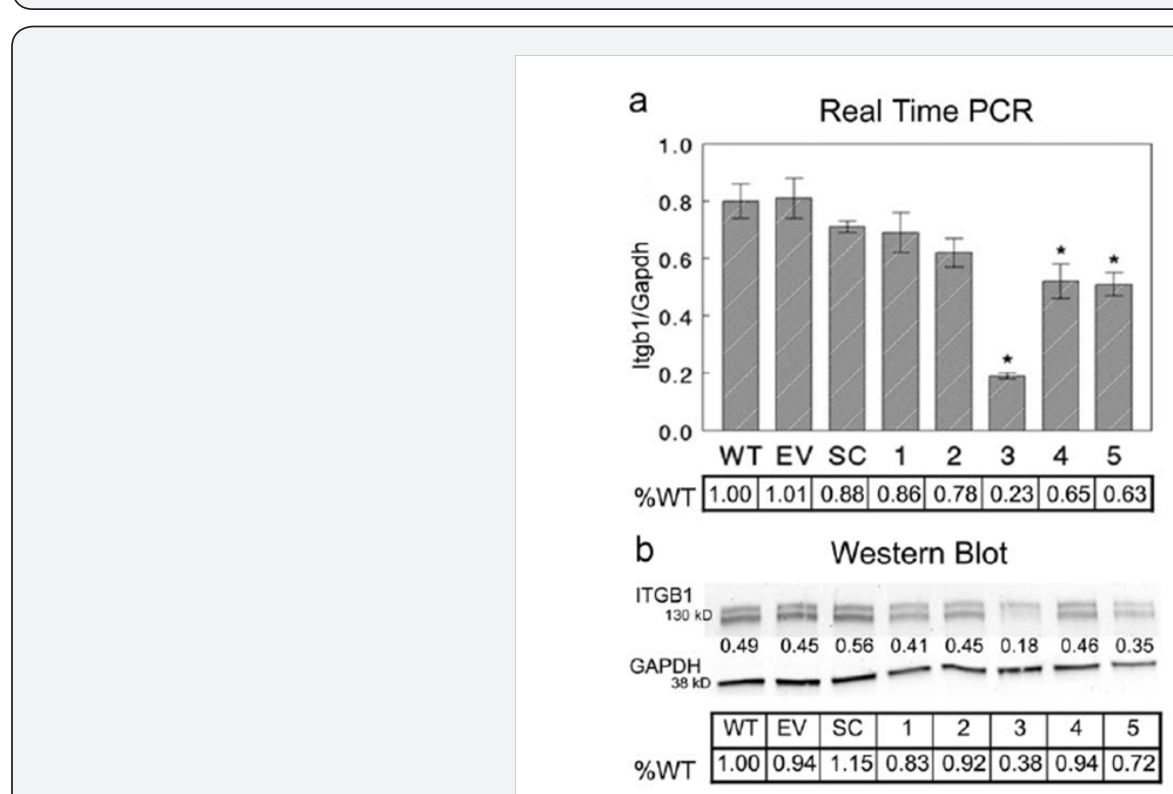

Supplemental Figure3: ATDC5 cells were either not transduced (WT), treated with empty viral particles without a plasmid (EV), a scrambled sequence plasmid not targeting Itgb1 (SC), or one of five plasmids introducing a sequence of shRNA targeted for degradation of mRNA (1-5). (a) Real-time PCR was performed on parallel cultures with these treatments and were assessed for mRNA expression levels of Itgb1. Percentage of WT value is shown in table below graph. ${ }^{*} \mathrm{P}<0.05 \mathrm{vs}$. WT. (b) Western blot was performed on cultures also grown in parallel with same treatments as in (a) and assessed for intensity of ITGB1 protein bands and GAPDH as a control. Value of the intensity of the ITGB1 bands (normalized by corresponding GAPDH intensity) is shown below ITGB1 bands and lower table indicates percentage of WT.

AsItgb1 mRNA levels exhibited a consistent increase in both cell types at the termination of shear stress, it was hypothesized that silencing Itgb1 would alter the response of ATDC5 cells under shear. A clone of ATDC5 cells was established with persistent reduction of Itgb1 mRNA. Levels of Itgb1 mRNA were shown to be significantly reduced in 3 of 5 tested clones targeted for silencing with one clone (clone 3 ) showing a 77\% reduction in mRNA expression compared to wild type ATDC5 cells (Figure S3a). The effects of the lentiviral delivery particles alone or a nonspecific plasmid sequence were not shown to alter Itgb1 mRNA levels. When assessed for reduction in protein expression, clone 3 also showed the greatest reduction in ITGB1 protein at $38 \%$ of the level in wild-type ATDC5 cells (Figure S3b). 


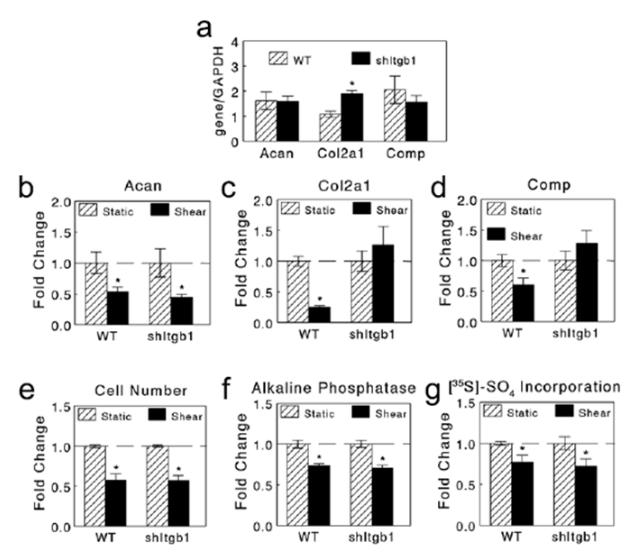

Figure 5: Silencing Itgb1 in ATDC5 cells does not alter shear effects on cell number, alkaline phosphatase activity or [35S]-sulfate incorporation, while it blocks shear-induced mRNA reduction of Col2a1 and Comp. (a) Baseline mRNA levels of aggrecan (Acan), collagen type II, apha 1 (COL2a1), and cartilage oligomeric matrix protein (Comp) were measured from WT and Itgb1-silenced (shltgb1) ATDC5 cells cultured in parallel to determine if silencing of Itgb1 altered baseline levels of these markers of interest. ${ }^{*}<0.05$ vs. WT for each gene.(b-d) WT or shltgb1 cells were sheared for 24 hours at 6.5 dynes $/ \mathrm{cm}^{2}$ and returned to static culture for 12 hours and then harvested for mRNA levels using real-time PCR and measured for Acan (b), Col2a1 (c), and Comp (d). Graphs are shown normalized to the average of the static control group. (e-g) WT and Itgb1-silenced ATDC5 cells (shltgb1) were exposed to 24 hours of shear stress at 6.5 dynes/cm² and then allowed to return to static culture for 24 additional hours and harvested for cell number (e), alkaline phosphatase activity (f), and [35S]-sulfate incorporation (g). ${ }^{*} \mathrm{P}<0.05$ vs. static control (b-g).

Baseline levels of mRNAs for Acan and Compwere not significantly altered by Itgb1 silencing, but Col2a1 mRNA levels were increased in the Itgb1-silenced ATDC5 cells (Figure 5a). Shear stress induced a reduction inAcanmRNA in both wild-type and Itgb1-silenced ATDC5 cells at 12 hours after shear (Figure 5b). Col2a1 mRNA in wild-type cells was reduced at 12 hours after shear at 6.5 dynes $/ \mathrm{cm}^{2}$ comparable to the above findings. However, it was not reduced significantly in Itgb1-silenced cells (Figure 5c). Similarly, Comp mRNA levels were reduced in wild-type cells but were not in silenced cells (Figure 5d). Shear treatment causes a comparable reduction in cell number inItgb1silenced and wild-type ATDC5 cells (Figure 5e). Similarly, the decrease in alkaline phosphatase activity (Figure 5f) and [35S]sulfate incorporation (Figure 5g) was not statistically different in Itgb1-silenced ATDC5 cells compared to wild-type cells.

\section{Discussion}

Our results demonstrate that growth plate chondrocytes are sensitive to fluid shear stress, and respond with reduced proliferation, differentiation, and ECM synthesis. The decrease in cell number in cultures exposed to 6.5 dynes $/ \mathrm{cm} 2$ shear stress was not simply an artifact of cell detachment by mechanical force, as demonstrated by comparable cell numbers between sheared and control groups atthetermination of treatment. The dramatic decrease in [3H]-thymidine incorporation observed following shear exposure indicates that this treatment almost completely ablated cell proliferation. While most cultures returned to baseline incorporation 24 hours after returning to static culture, it is possible that proliferation rates were not restored until almost the end of that recovery time. This may explain why in one experiment, DNA synthesis was not fully recovered at 24 hours following shear. Cessation of proliferation after initiating shear, along with a slow recovery to normal levels following shear, may contribute substantially to the decreased cell number observed at 24 hours of post-shear static culture.

These experiments do not indicate whether apoptosis was induced by shear. Studies have reported that shear can induce apoptosis in chondrocytes via production of nitric oxide [30], so it is possible that apoptosis also contributed to ashear-induced reduction in cell number. The high level of positive viability staining suggests that cells have not undergone significant apoptosis at the end of shear. However, theultimate onset of apoptosis might occur during the static period following treatment in sheared groups, thus possibly contributing in part to the observed decrease in cell number at 24 static hours after shear. Future work should more fully characterize the timing and severity of any shear-induced apoptosis.

Our results show that fluid shear stress reduced alkaline phosphatase specific activity, but it is not clear whether this indicates a delay or reduction of endochondral differentiation or expression of a more mature hypertrophic phenotype. Alkaline phosphatase is indicative of differentiation state for both chondrocytes [31,32] and osteoblasts [33,34]. It is elevated at early stages of endochondral differentiation in the growth plate, but at later stages, activity is reduced. We did not assess type $\mathrm{X}$ collagen expression, which is a marker of later stage endochondral maturation of growth plate chondrocytes. Thus, a definitive statement cannot be made at this time.

Alkaline phosphatase has not previously been reported as sensitive to fluid shear stress in resting zone chondrocytes, 
although it was shown to be decreased by cyclical strain in hypertrophic growth plate chondrocytes [35]. Shear stress both increases and decreases alkaline phosphatase activity in osteoblasts, depending on the magnitude of shear stress, time of exposure, and even the roughness of the cell substrate surface [36-38]. Thus fluid shear stress effects on alkaline phosphatase activity may vary by cell type, duration and dose of shear, and the extracellular environment. Overall, response to shear was similar in the two cell types, suggesting that reduced alkaline phosphatase activity may be a general property of growth plate chondrocytes.

Shear stress affected ECM production by resting zone chondrocytes and ATDC5 chondrocytes. We assessed effects on proteoglycan by measuring mRNA levels for Acan, which is the core protein of cartilage proteoglycan, and by measuring [35S]sulfate incorporation as an indicator of glycosaminoglycan sulfation. Both parameters were significantly reduced by shear, but reduction levels waned after a static recovery period. This finding supports the conclusion that resting zone chondrocytes and ATDC5 cells produce less cartilage matrix during shear exposure, but once shear ceases then production of core protein and sulfation of associated glycosaminoglycans resumes. The observed decrease in [35S]-sulfate incorporation may be due to decreased production of proteoglycan molecules, either due to reduced Acan expression as suggested by the reduction in A can mRNA, or to decreased sulfation of existing glycosaminoglycans, but increased breakdown of proteoglycans may have played a role as well. It has been reported that mechanical stimuli can alter the expression of aggrecanases [39], which can break down proteoglycan molecules.The effect of shear on aggrecanase production or activity has not yet been studied in our system.

Shear also affected the mRNA levels of other important matrix molecules. Our results suggest that exposure to shear initiated a reduction in Col2a1 and Comp expression. COMP provides a three-dimensional network throughout the cartilage ECM that can serve to organize and stabilize the collagen/proteoglycan aggregate composite hydrogel $[40,41]$. COMP is upregulated in articular chondrocytes by cyclic compression [14] and cyclic tension [42], indicating that this matrix molecule likely has a major role in responding to mechanical stimulation. However, our results suggest that COMP may be regulated differently in growth plate cells by laminar fluid shear stress, resulting in decreased expression. Integrin subunit mRNA expression was upregulated by fluid shear stress. This finding together with the consistent decrease in chondrocytic mRNA, sulfate incorporation, and alkaline phosphatase activity observed after 24 hours of shear stress suggest the cells reduce metabolic maintenance of chondrocytic markers and reallocate resources towards a potential increase in integrin expression during shear conditions. Augmented integrin expression could allow the cells to form more focal adhesions, preparing them to better endure the enhanced mechanical environment during shear [43].
Silencing of Itgb1 did not prevent the shear-induced decrease of cell number, alkaline phosphatase activity, sulfate incorporation, or Acan mRNA, suggesting other mediators are involved in these responses to shear stress. However, silencing of Itgb1 did block shear-induced reduction in mRNA levels for Col2a1 and Comp, suggesting mediation by ITGB1 in these responses. It may be possible that shear stress induces additional motion and spreading of the cellular membrane, which may influence the kinetic rates of integrin receptor interaction with ligand proteins in the matrix [44]. Interestingly, both collagen type II [45] and COMP [46] are capable of ligand binding with ITGB1 when paired with the appropriate dimeric alpha subunit. Our baseline comparison of silenced versus wildtype cells indicates when Itgb1 is silenced there is a resulting increase in Col2a1 mRNA. This may be caused by a reduction of integrin-associated intracellular and autocrine signals [47] that might serve as a negative feedback system [48] to the cell to inform when sufficient levels of collagen type II are already present in the matrix.If the cell does not receive these signals, it may result in a net increase in basal expression of Col2a1. We did not assess if Itgb1 silencing altered expression levels of other integrin subunits. However, our lab has shown thatItga2silenced osteoblasts exhibited no changes in the expression levels of other integrin subunits, suggesting that integrins may be regulated in dependently from each other [49].

If shear stress did increase integrin signaling by increasing kinetic receptor interaction, then sheared wild-type cells may sensecollagen type II in the matrix at a faster rate and decrease levels of mRNA for this gene. The silenced cells may not correctly detect the extracellular levels of collagen type II present due to the diminished presence of receptor, and thus the cells would not reduce levels of Col2a1 mRNA during shear. This may also explain why Col2a1 and Comp mRNA levels decreased after the cessation of shear, and integrin mRNA increased by the end of shear. The more frequent interaction of integrins with COL2A1and COMP could signal to the cells a high ratio of ligand to receptor activity, ultimately promoting decreased ligand and increased receptor production. Future work should determine the response to shear at additional time points to delineate if silencing Itgb1 resulted in a truly blocked effect or an alteration in therate of production of integrins and their ligands.

Yokota et al. [50] showed short exposure times ( 1 hour) at 5 dynes/cm2 fluid flow were beneficial to a chondrocytic cell line whereas destructive responses were upregulated at 20dynes/ $\mathrm{cm} 2$. The cells studied in our system were unresponsive to short periods of shear stress ( 2 hours, data not shown), and reduced markers of differentiation when exposed for 24 hours to the range of shear stresses applied, suggesting not all chondrocytes respond equally to the same stimuli or on the same time scale. It is not well understood what shear stresses growth plate chondrocytes are exposed to in vivo and how they may differ from stresses in other cartilaginous tissues. The differences in 
matrix composition associated with endochondral development and the corrugated anatomy of the growth plate also make it difficult to model this important parameter. While our results have certain limitations for in vivo correlation, this study was also intended to study how fluid flow bioreactor parameters might enable better culture processes of less mature (resting-zone stage) chondrocytes for cartilage or osteochondral constructs. However, our results suggest that fluid shear may generally not be suitable for promoting differentiation of less mature chondrocytes. Compressive forces can suppress longitudinal bone growth in rats [51], suggesting that growth plates are inhibited by this form of mechanical stimulation. Moreover, recently characterized mineral tethers that can span the length of the growth plate [52], may serve to reduce the compression and loading that is experienced in this cartilage as compared to articular cartilage. Overall, growth plate chondrocytes may be more shielded from fluid shear stress compared to chondrocytes located at articular surfaces, and thus perhaps not fully developed to respond to mechanical signals in normal homeostatic ways.

The consistent patterns observed in ATDC5 cells as compared to primary rat resting zone chondrocytes indicate that ATDC5 cells are potentially a good model to study this cell type under mechanical loading. The present study shows that growth plate chondrocytes can sense fluid shear; future studies can use these models to elucidate the underlying mechanisms involved further.

\section{Acknowledgement}

This work was supported by National Science Foundation Grants EEC-9731643 and IGERT-0221600, National Institutes of Health Grant 1246638, and Children's Healthcare of Atlanta. Thank you to Dr. Hanjoong Jo for helping us establish our coneplate shear device used in this study.

\section{Conflict of Interest}

The authors declare they have no conflict of interest that would bias the work presented in this study.

\section{References}

1. Dolinak D, Matshes EW, Lew EO (2005) Forensic Pathology: Principles and Practice. Elsevier Academic Press pp: 663.

2. Srivastava PC, Shikha Saxena S and Sahai MKB (2009) Medical Certification of cause of death. Internet J Med Update 4(1): 56-58.

3. Committee for the Workshop on the Medicolegal Death Investigation System (2003) Medicolegal Death Investigation System Workshop Summary. The National Academy Press, USA.

4. WHO Report (2002) Reducing Risks: Promoting Healthy Life. World Health Organization, Europe.

5. Suvedi BK (2007) Of what diseases are Nepalese people dying? Kathmandu Univ Med J (KUMJ) 5-1(17): 121-123.

6. Kotabagi Col RB, Chaturvedi Col RK, Banerjee Col A (2004) Medical Certification of Cause of Death. MJAFI 60(3): 261-272.

7. Prasad BK, Prasad C (2003) Road traffic accident (RTA) as major killer: A report on medicolegal autopsies in Bharatpur hospital. Kathmandu University Med J 1(1): 34-35.
8. Linden CH, Burns MJ, Mycyk MB (2008) Poisoning, drug overdose and envenomation. In: Fauci AS (ed), Harrison's Principles of Internal Medicine. McGraw-Hill, USA, pp: 2741-2748.

9. Maskey A, Parajuli M, Kohli SC, Baral S, Basnet S, et al. (2012) Scenario of Poisoning Cases in Adults Admitted in Manipal Teaching Hospital, Pokhara, Nepal. Nepal J Med Sci 1(1): 23-26.

10. Haloi M, Haloi DM, Patowary A (2013) Death due to Poisoning in District of Kamrup, Assam: A Medico-legal Study. J Indian Acad Forensic Med 35 (1).

11. Chakrabarti K1, Devkota KC (2001) Retrospective study of poisoning cases admitted in Nepal Medical College Teaching Hospital. Nep Med Col J 3: 101-105.

12. Gupta SK, Joshi MP (2001) Pesticide poisoning cases attending five major hospital of Nepal. J Nep Med Assoc 41:447-56.

13. Bajracharya MR, Manandhar K, Deo KK (2008) Age and gender distribution in deliberate self poisoning Cases PMJN 8: 44-49.

14. Yurumez Y, Durukan P, Yavuz Y, Ikizceli I, Avsarogullari L, et al (2007) Acute organophosphate poisoning in university hospital emergency room patient. Intern Med 46(13): 965-969.

15. Pokhrel N, Gurung CK (1987) A study of poison cases recorded in Bir hospital over four years. J Inst Med 9: 29-34.

16. Kafle KK (1989) Poisoning cases at T.U. Teaching hospital. J Inst Med 11: 297-301.

17. Rauniyar GP (1999) Retrospective Analysis of profile of acute poisoning case in a tertiary care hospital in eastern Nepal: A four year data base from 1994 to 1997. J Nep Med Assoc 38: 23-8.

18. Khadka SB and Ale SB (2005) A study of poisoning cases in emergency Kathmandu Medical College Teaching Hospital. Kathmandu University Med J 3(4): 388-391.

19. Vij K (2001) Textbook of Forensic Medicine, Principles and Practice (1 $1^{\text {st }}$ edn.). Churchill Livingstone Pvt, India, pp: 62.

20. Kafle KK, Kumar G (1992) Organophosphorous - commonest poisoning agent. Journal of Institute of Med 14: 228-233.

21. Parikh CK (1990) Text Book of Medical Jurisprudence \& Toxicology $\left(5^{\text {th }}\right.$ edn). CBS Publishers. Deaths from Asphyxia - Hanging, pp: 186-194.

22. Modi JP (2002) Medical Jurisprudence \& Toxicology (22 $2^{\text {nd }}$ edn). LexisNexis Butterworths, Deaths from Asphyxia - Hanging, pp: 251260.

23. Knight B (1996) Forensic Pathology ( $\left.2^{\text {nd }} e d n\right)$. Oxford University Press, USA, pp: $345-360$

24. Nair S, Jacob J, Aaron S, Thomas M, Joseph M, et al. (2009) Pulmonary distress following attempted suicidal hanging. Indian J Med Sci 63(2): 53-57.

25. Fischman CM, Goldsmith MS, Gardner LB (1977) Suicidal hanging an association with the adult respiratory distress syndrome. Chest 71(2): 225-227.

26. Digeronimo RJ, Mayes TC (1994) Near-hanging injury in childhood: A literature review and report of three cases. Pediatr Emerg Care 10(3): 150-156.

27. Kaki A, Crosby ET, Lui AC (1997) Airway and respiratory management following non-lethal hanging. Can J Anaesth 44(4): 445-450.

28. Hoff BH (1978) Multiple organ failure after near-hanging: A case report. Crit Care Med 6(6): 366-369.

29. Saiyed MZG, Modi KA (2013) Retrospective Study of Postmortem Cases of Hanging - A Method of Suicide. NHL Journal of Medical Sci 2(2): 4850 . 
30. Pradhan A, Tripathi CB, Mandal BK, Karn A, Subedi ND (2012) Suicide: Attempts Methods and Causes in Cases Brought for Autopsy in BPKIHS Dharan. J Forensic Res 3(9): 1-3

31. Urmila B, Bahadur SJ, Madhusudan S (2001) Study of Acute poisoning in Nepal Medical College Teaching Hospital. NMCJ 2(2): 83-85.

32. Narayan PP, Prakash K (1997) Poisoning cases at TUTH Emergency-A one-year review. Journal of the Institute of Medicine 19: 18-24.
33. Statistisches Bundesamt (2013) Todesursachen in Deutschland 2011. Statistisches Bundesamt, Germany 2013.

34. WHO (1992) International statistical classification of diseases and related health problems, Tenth revision. World Health Organization, Geneva.

35. Dimaio VI and Dimaio D (2001) Forensic Pathology (2 ${ }^{\text {nd }}$ edn). CRC Press, USA, pp: 245-325.

\section{Your next submission with Juniper Publishers will reach you the below assets}

- Quality Editorial service

- Swift Peer Review

- Reprints availability

- E-prints Service

- Manuscript Podcast for convenient understanding

- Global attainment for your research

- Manuscript accessibility in different formats

( Pdf, E-pub, Full Text, Audio)

- Unceasing customer service

Track the below URL for one-step submission https://juniperpublishers.com/online-submission.php 